\title{
Erratum to: Structure and palaeoenvironmental implications of inter-branch coenosteum-rich skeleton in corymbose Acropora species
}

\author{
J. Sadler ${ }^{1}$ G. E. Webb ${ }^{1}$ L. D. Nothdurft ${ }^{2}$
}

Published online: 6 June 2015

(C) Springer-Verlag Berlin Heidelberg 2015

\section{Erratum to: Coral Reefs (2015) 34:201-213 DOI 10.1007/s00338-014-1228-0}

Please note an error in Fig. 12 where $\mathrm{Sr} / \mathrm{Ca}$ values are incorrectly reported with units of $\mu \mathrm{mol} / \mathrm{mol}$. Correct y-axis labelling should $\mathrm{read} \mathrm{Sr} / \mathrm{Ca}(\mathrm{mmol} / \mathrm{mol})$. Trace element analysis was carried out on a Thermo X Series II quadruple ICP-MS, not the multi-collector ICP-MS as described in the manuscript.

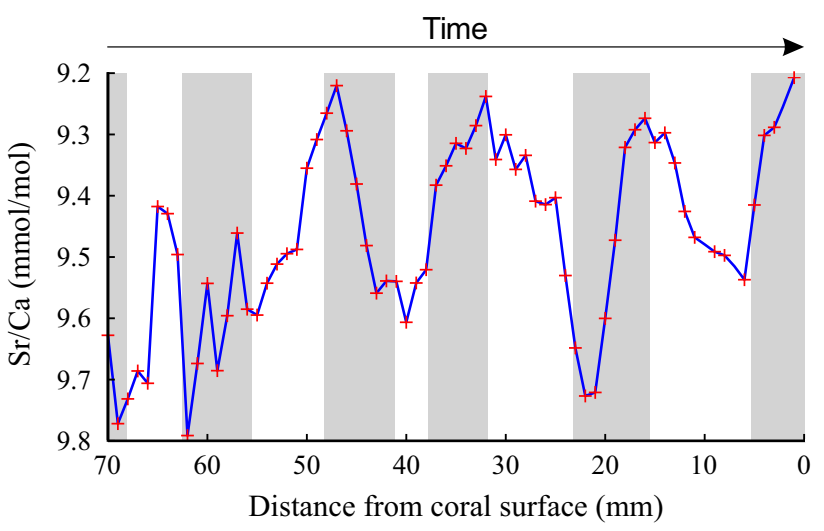

Fig. 12 Geochemical analyses from Acropora inter-branch coenosteum with the living surface on the right. Sr/Ca ratios of coarse samples $(1 \mathrm{~mm}$ resolution) display clear oscillation in the first 53 samples that correlates roughly with high and low density bands (grey and white backgrounds, respectively), potentially reflecting seasonal changes in water temperature. Samples 54-70 contained small volumes of branch material within the inter-branch coenosteum that reduces the signal quality. Regardless, the correlation is consistent with the density banding being annual in nature. Note that the $\mathrm{Sr} / \mathrm{Ca}$ axis is inverted to provide a profile similar to water temperature
The online version of the original article can be found under doi:10.1007/s00338-014-1228-0.

\section{J. Sadler}

j.sadler@uq.edu.au

1 School of Earth Sciences, The University of Queensland, St. Lucia, QLD 4071, Australia

2 School of Earth, Environmental and Biological Sciences, Queensland University of Technology, Brisbane, QLD 4001, Australia 